\title{
REVIEW
}

\section{Systemic Treatment of Adult Atopic Dermatitis: A Review}

\author{
Matteo Megna - Maddalena Napolitano - Cataldo Patruno · \\ Alessia Villani · Anna Balato · Giuseppe Monfrecola · Fabio Ayala • \\ Nicola Balato
}

Received: November 17, 2016 / Published online: December 26, 2016

(c) The Author(s) 2016. This article is published with open access at Springerlink.com

\section{ABSTRACT}

Atopic dermatitis (AD) is a common chronic inflammatory skin disease that predominantly affects children. However, it can persist in adulthood and/or start at older ages. Due to its chronic nature and frequently occurring relapses, $\mathrm{AD}$ has a substantial effect on patients' quality of life, often requiring long-term systemic treatment, especially in adult patients, who are more frequently refractory to adequate topical treatment with mid- to high-potent corticosteroids and/or calcineurin inhibitors. Therefore, treatment with systemic therapies is often needed to take control of the disease, prevent exacerbations and improve quality of life. However, data regarding systemic treatment effectiveness and long-term safety in adult patients with $\mathrm{AD}$ are insufficient. Indeed, standardized international

Enhanced content To view enhanced content for this article go to http://www.medengine.com/Redeem/ 7E47F06070094227.

M. Megna ( $₫) \cdot$ M. Napolitano · C. Patruno

A. Villani - A. Balato - G. Monfrecola · F. Ayala .

N. Balato

Department of Dermatology, University of Naples

Federico II, Naples, Italy

e-mail: mat24@libero.It guidelines are lacking, and the treatment approach widely differs among diverse countries. This review focuses on the use of systemic treatments in adult $\mathrm{AD}$ patients analyzing published literature.

Keywords: Adult atopic dermatitis; Biologics; Atopic dermatitis; Systemic treatments

\section{INTRODUCTION}

Atopic dermatitis (AD) is a common chronic inflammatory skin disease that predominantly affects children. Indeed, it shows a prevalence up to $20 \%$ in children $[1,2]$. However, although in $60 \%$ of patients $\mathrm{AD}$ manifests in childhood, it can start at any age [3]. Prevalence data on adult $\mathrm{AD}$ are variable, reporting percentages ranging from $1 \%$ to $10 \%[1,2,4]$. However, recent studies suggest that the prevalence of both persistent disease (AD developed in childhood with a chronic relapsing course until adulthood) and adult-onset disease (AD directly started later in life, i.e., after 18 years of age) is increased over time along with an increase in the incidence of childhood AD [3-6]. 
Therefore, it is conceivable that adulthood AD cases tend to be more frequent than in the past when it was commonly believed that the disease usually disappeared in late childhood in up to $60 \%$ of cases [7]. The course of $\mathrm{AD}$ can be continuous for long periods or showing a relapsing-remitting nature with repeated flare-ups. Since AD in adults, especially for persistent disease, is frequently refractory to adequate topical treatment with mid- to high-potent corticosteroids and/or calcineurin inhibitors, a long-term treatment with oral immunosuppressive therapy is often required to control the burden of the disease, prevent flare-ups and achieve better patient quality of life outcomes [4, 8, 9]. However, systemic treatment of adult $\mathrm{AD}$ has not been well characterized yet, and data for the long-term safety and comparative effectiveness of systemic immunosuppressive therapies are insufficient. Therefore, large variations exist in adult $\mathrm{AD}$ systemic treatment approaches worldwide also because of the lack of international standardized guidelines. The current review focuses on the use of systemic therapies in adult $\mathrm{AD}$ patients, analyzing existing literature.

\section{METHODS}

We searched for English-language literature regarding systemic therapies in adult $\mathrm{AD}$ patients in the following databases through 10 October 2016: PubMed, Embase, The Cochrane Library, Google Scholar, EBSCO and Scopus. The following key words were used: "adult atopic dermatitis," "adult atopic eczema," "systemic treatment," "systemic therapy," "atopic dermatitis," "adulthood," "adult," "phototherapy," "corticosteroids," "cyclosporine," "methotrexate," "azathioprine," "mycophenolic acid," "mycophenolate mofetil," "alitretinoin," "apremilast," "rituximab," "biologics," "ustekinumab," "omalizumab" and "dupilumab." All the published articles (case report, case series, prospective and retrospective studies, clinical trials, reviews, guidelines, and consensus) were reviewed to provide a complete overview of systemic therapy for adult $\mathrm{AD}$ patients, also giving detailed data about new targeted therapies, which represent an exciting perspective for the management of severe forms of adult AD. This article is based on previously conducted studies and does not involve any new studies of human or animal subjects performed by any of the authors.

\section{Adult AD Management: Systemic Therapy}

When topical treatments fail, systemic therapies are required. Adult $\mathrm{AD}$ management is challenging and should integrate a therapeutic education program. Systemic treatments are recommended in severe, chronic and resistant forms of $\mathrm{AD}$, after careful evaluation in a reference center [4, 5]. In 2008, a survey analyzing a representative sample of 11,555 patients (60\% adults) with $\mathrm{AD}$ enrolled from a population-based administrative health care database confirmed insufficient care and medical treatment of $\mathrm{AD}$ in routine practice [10]. Moreover, the literature is constantly enriched by studies that show adult $\mathrm{AD}$ as a possible systemic disease, being associated with metabolic and cardiovascular comorbidities further complicating treatment of these patients with systemic drugs (e.g., alitretinoin should be carefully used for patients with dyslipidemia, cyclosporine should be carefully used in patients with hypertension, etc.) [11-15]. Systemic antiinflammatory therapy is appropriate for severe $\mathrm{AD}$ patients; about 10\% of adult patients receive systemic antiinflammatory therapy at some point during the course of their disease, while in 
children it is rarely employed [16]. Long-term treatment with oral immunosuppressive therapy is usually introduced when topical treatment with mid- to high-potent corticosteroids and/or calcineurin inhibitors is not successful. Cyclosporine is the most widely used agent, administered with excellent effects as short-term treatment as well as maintenance therapy in both adults and children [17]. In addition, other immunosuppressive agents such as azathioprine, mycophenolate mofetil and methotrexate may be helpful for the treatment of relapsing and severe forms of $\mathrm{AD}[17,18]$. However, it is usually important to combine these immunosuppressive treatments with topical therapy to better control the burden of the disease [19]. Ultraviolet (UV) therapy is another alternative treatment to consider when topical treatments fail. Narrow-band UVB radiation and medium-dose UVA1 have been reported to be effective for $\mathrm{AD}$, in particular for AD patients resistant to topical corticosteroids or patients experiencing side effects due to systemic treatments [20]. However, data regarding systemic treatment effectiveness and long-term safety in adult AD are limited, and further studies are needed also to standardize and regulate their use among different countries $[1,4,21-24]$.

\section{Phototherapy}

Artificial UV radiation is frequently used as a second-line treatment for moderate-to-severe $\mathrm{AD}$ in adults $[24,25]$. By reducing the number of epidermal nerve fibers and the expression of axon guidance molecules, it is also considered a good therapeutic approach for AD-associated itch, relieving patients from this oppressive symptom [26, 27]. Moreover, UV irradiation is also able to modulate the immune response of $\mathrm{AD}$ patients via upregulation of FoxP3-positive regulatory $\mathrm{T}$ cells, whose number is directly correlated with the degree of AD severity score improvements [28]. Different artificial light sources are available against $\mathrm{AD}$ : broadband UVB (290-320 nm), narrow-band (NB) UVB (311-313 nm), excimer laser (308 nm), UVA-1 (340-400 nm), psoralens and UVA (PUVA), and combined UVA/UVB (280-400 nm). Their efficacy is linked to the ability to inhibit DNA synthesis and keratinocyte proliferation, suppression of the antigen-presenting function of the Langerhans' cells, $\mathrm{T}$ lymphocyte apoptosis induction and antiinflammatory mediator production [29]. A complete review of the published literature on this topic, including a total of 428 studies regarding the efficacy and safety of phototherapy [30], as well as an up-to-date review on 19 randomized controlled trials (including 905 participants) [31] confirmed that medium-dose UVA1 and NB-UVB phototherapies are the most effective and safe modalities for adult $\mathrm{AD}$ treatment as also observed in various randomized controlled trials and other studies [24, 32-37]. As a rule, phototherapy is not indicated in the acute stage of AD (except UVA1, which is also effective in managing AD flares) [38-40], but is more apt to treat chronic, pruritic, lichenified forms [24, 35], and should not be prescribed in those patients who experience a worsening of their dermatosis during sun exposure as in the case of other common chronic inflammatory diseases such as psoriasis [41]. In general, NB-UVB has been indicated for chronic-moderate forms of $\mathrm{AD}$ and is currently preferred to broadband UV because it is less erythemogenic; a recent study reported that the combination with UVA did not show any further benefits [42]. On the other hand, medium-dose UVA1 appears to be similar to NB-UVB in terms of efficacy, as shown in different studies [43, 44]. In summary, phototherapy can be used as both short- and 
long-term treatment with variable scheduling including a minimum of thrice weekly access [45]. Nevertheless, it is considered a safe and well-tolerated therapeutic approach, it is limited by the inconvenience and possible adverse events, including limited access to in-office treatment, difficulty adhering to a thrice-weekly schedule, erythema, photodamage, actinic keratosis, blistering and herpes virus reactivation. On the other hand, long-term side effects such as premature photoaging and carcinogenesis have not been excluded [35, 37]. Safe use of NB-UVB and medium-dose UVA1 has been well documented, and it was cited as the most commonly used wave length and modality of light-based therapy for $\mathrm{AD}$ [30, 31, 34, 45]. UV can also be combined with a prior (oral or topical) administration of photosensitizing drugs such as psoralens (photochemotherapy). Psoralens are used with UVA (PUVA). Generally, photochemotherapy is not considered the first phototherapy modality of treatment, especially for oral PUVA, which may present several side effects including nausea, headache, fatigue, burning skin, itching and irregular skin pigmentation as well as a higher risk of skin cancer, so that the risk/benefit ratio of this treatment must be carefully weighed [24, 31, 45]. Moreover, it should be also stated that most patients favor NB-UVB or UVA1 phototherapy as they are easier to perform and do not require the concomitant administration of a photosensitizer. However, studies on photochemotherapy used in adult $\mathrm{AD}$ patients are less numerous with respect to NB-UVB or UVA1. In a crossover study on 23 patients, Tzaneva et al. reported that 5-methoxypsoralen (MOP) PUVA was significantly better than medium-dose UVA1 for the reduction of SCORing Atopic Dermatitis (SCORAD) and the duration of remission [46], while Uetsu et al. reported a large series of 113 Japanese subjects (mean age 27.5 years) with severe $\mathrm{AD}$ in which 8-methoxypsoralen (8-MOP) PUVA led to a reduction of $51 \%$ and $80 \%$ of the $\mathrm{AD}$ severity score at 4 and 8 weeks of treatment, respectively, without severe adverse effects [47]. In addition, a study on 12 adult $\mathrm{AD}$ patients showed comparable efficacy between 8-MOP bath PUVA and NB-UVB when applied in threshold erythemogenic doses [48]. The efficacy of 8-MOP bath PUVA was also reported by de Kort et al., suggesting that it may represent a most welcome addition to the existing therapies for extensive atopic eczema also because of the lack of systemic side effects with respect to oral PUVA [49]. However, despite this evidence, photochemotherapy still remains a less frequently used and investigated treatment modality for adult $\mathrm{AD}$ with respect to NB-UVB and UVA1.

In conclusion, phototherapy can be used as both short- and/or long-term treatment. Topical steroids and emollients can be associated with phototherapy to reduce flare-ups, whereas calcineurin inhibitors may be avoided to limit the carcinogenesis risk [45]. There are no guidelines or studies on combination treatment of phototherapy and systemic drugs for adult AD. Generally, a combination therapy of cyclosporine with UV therapy is not indicated because the incidence of cutaneous malignancies may be increased [24]. Although evidence supporting the efficacy and tolerability of phototherapy is well established, long-term data and quantification of its possible carcinogenesis risk in adult $\mathrm{AD}$ patients are still limited.

\section{Non-Biologic Systemic Drugs}

Severe and recalcitrant forms of $\mathrm{AD}$ in adult patients require systemic immunosuppressive 
treatments. Non-biologic systemic drugs used for adult $\mathrm{AD}$ include corticosteroids, cyclosporine, azathioprine, mycophenolate mofetil and methotrexate, which exert their immunosuppressive effects by reducing the disease inflammatory cell numbers and proinflammatory cytokines expression [50]. All these agents are used off label, except for cyclosporine, which is licensed and approved for short-term treatment of severe refractory AD in many European countries [24]. Recommendations for the use of these immunosuppressive drugs derive from randomized clinical trials that have been published to support daily practice in the management of adult patients with $\mathrm{AD}$ [24, 51]. In 2014 Garritzen et al. published a medical chart review providing a complete overview of systemic immunosuppressive drugs and evaluating their effectiveness and safety during 10-year treatment in a total of 334 AD adult patients (mean age 36.89 years) [1] During this period, cyclosporine was administered to the majority of patients (80\%), followed by mycophenolate mofetil or enteric-coated mycophenolate (31\%), azathioprine (14\%), methotrexate (11\%), systemic glucocorticosteroids (7\%) and systemic tacrolimus (5\%). Therefore, cyclosporine represented the first choice for adult $\mathrm{AD}$ treatment with oral immunosuppressive drugs; however, adverse events were frequent reasons for its discontinuation [1]. Furthermore, a single-center retrospective study including 129 adult patients with moderate-to-severe AD was conducted to compare the long-term efficacy and safety of systemic drugs during a 14-year period [18]. Systemic therapies were prescribed to 54 out of these 129 (41.9\%) adult $\mathrm{AD}$ patients. Cyclosporine was the most frequently prescribed drug $(n=43,79.6 \%)$, followed by methotrexate ( $n=28,51.8 \%)$ and azathioprine $(n=17,31.5 \%)$, whereas seven patients (13\%) were administered a combination therapy with methotrexate and azathioprine. The mean treatment durations were 35.7, 21.1, 42.5 and 19.1 months for methotrexate, azathioprine, cyclocporine and a combination of methotrexate and azathioprine, respectively [18]. An overview of systemic treatments for adult AD is displayed in Table 1.

\section{Oral Corticosteroids}

Systemic corticosteroids are rapidly effective as short-term therapy (3 days to 3 weeks) to interrupt acute flare-ups in patients with severe $\mathrm{AD}$, but their use for long-term treatment is not recommended because of the possible numerous side effects [24, 50, 52]. Corticosteroids affect the transcription of several mediators involved in the pathogenesis of $\mathrm{AD}$, including cytokines, chemochines and adhesion molecules, by binding to regulatory elements of many genes via their receptors, resulting in inhibition of cell proliferation, vasoconstriction and resolution of inflammation [50]. Although broad experience from clinical use by many experts indicates systemic corticosteroids' efficacy in $\mathrm{AD}$, controlled clinical trials in both children and adults are lacking. Data obtained from a study analyzing 21 adult patients with severe eczema suggested that treatment with oral prednisolone (0.5-0.8 $\mathrm{mg} / \mathrm{kg}$ daily) for 2 weeks was not able to induce a stable remission of $\mathrm{AD}$, even when associated with topical steroids [53]. Moreover, even though the authors also demonstrated equal efficacy of therapy with systemic glucocorticosteroids as cyclosporine analyzing 21 vs. $17 \mathrm{AD}$ patients, respectively, they concluded that despite its frequent use in daily practice, prednisolone is not recommended to induce stable remission of eczema [53]. 


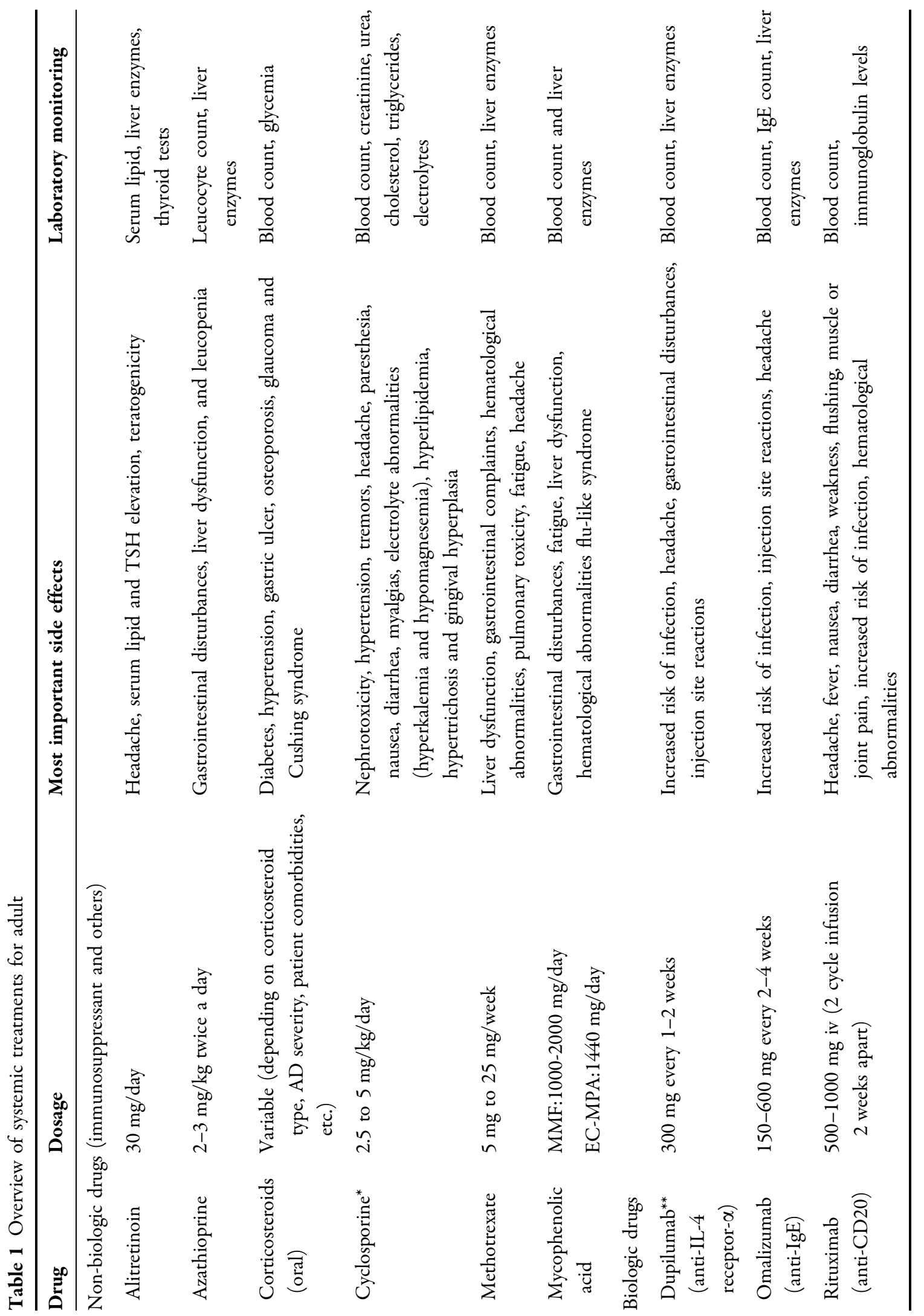




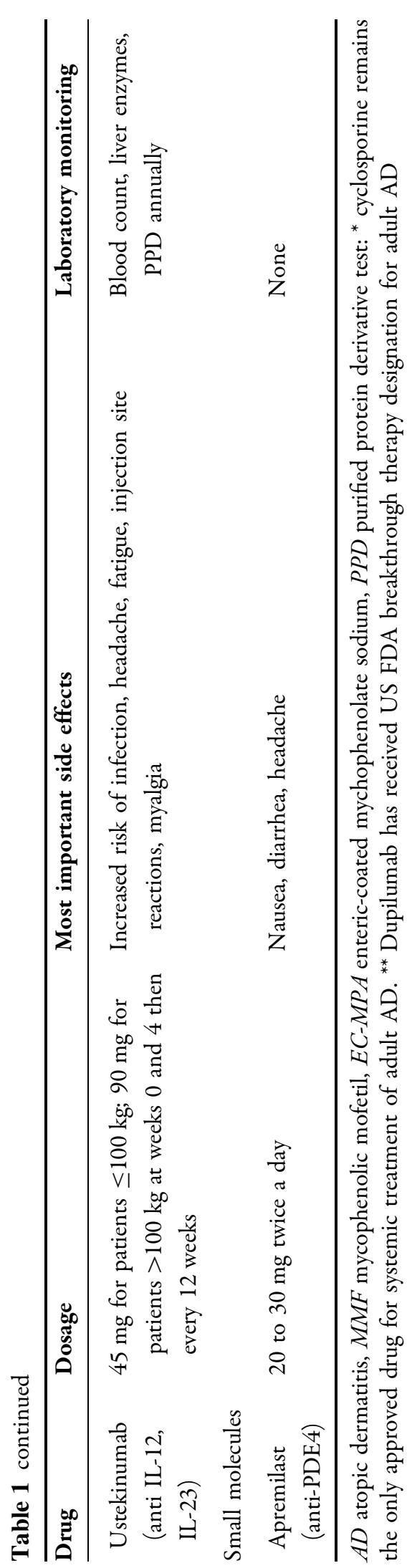

Although oral corticosteroids improve the clinical symptoms of $\mathrm{AD}$, their administration should generally be avoided because of their well-known potential side effects. They include diabetes, hypertension, gastric ulcer, osteoporosis, glaucoma and Cushing syndrome. Moreover, increased production of immunoglobulin $\mathrm{E}$ (IgE) by $\mathrm{B}$ cells in $\mathrm{AD}$ patients has been reported after treatment with oral prednisolone, potentially supporting the pathogenesis of extrinsic forms of $\mathrm{AD}$ [53-55]. Moreover, the dosage of oral prednisolone during short-term treatment of AD should be accurately tapered to avoid the development of serious relapses and rebound of the disease [53]. Indeed, rebound flare is frequently observed after the abrupt cessation of systemic corticosteroids [21, 24, 56]. In summary, systemic steroids have a largely unfavorable risk/benefit ratio for adult $\mathrm{AD}$ treatment. Long-term use in adult $\mathrm{AD}$ is not recommended; only short-term (up to 1 week) treatment may be an option to treat an acute flare in exceptional and severe cases of AD.

\section{Cyclosporine}

Cyclosporine is the first choice for systemic treatment of moderate-to-severe $\mathrm{AD}$ patients who are unresponsive to topical therapy and oral antihistamines [57]. It is an immunomodulatory drug that inhibits interleukin (IL)-2 and the function of $\mathrm{T}$ lymphocytes. The dosage is commonly started with $2.5 \mathrm{mg} / \mathrm{kg} /$ day and increased by $0.5-1 \mathrm{mg} /$ $\mathrm{kg} /$ day at 2- to 4-week intervals, up to $5 \mathrm{mg} /$ $\mathrm{kg} /$ day. Compared to this treatment scheme, faster induction can be achieved by starting treatment with a high dose relative to body weight ( $5 \mathrm{mg} / \mathrm{kg} /$ day) and reducing the dose by $0.5-1.0 \mathrm{mg} / \mathrm{kg} /$ day every 2 weeks until the achievement of clinical benefits [58]. Based on the results of randomized controlled trials on 
adult patients, cyclosporine has been approved for the short-term treatment of adults with severe AD. However, even though it can also be used as a continuous therapy, a maximum duration of 1-2 years has been recommended to avoid side effects [57]. The most common and important side effects include nephrotoxicity, hypertension, tremors, headaches, paresthesia, nausea, diarrhea, myalgias, electrolyte imbalance, hyperlipidemia, hypertrichosis and gingival hyperplasia [21]. A detailed patient monitoring, especially of the renal status, is required before and after cyclosporine administration. Blood pressure should be frequently measured, and laboratory testing should be performed every 3 months during a long-term treatment [59]. Rare cases of cutaneous $\mathrm{T}$ cell lymphoma, non-Hodgkin's lymphoma and lymphomatoid papulosis in adult $\mathrm{AD}$ patients on cyclosporine therapy have been reported [60-62]. A double-blind, controlled, crossover study including $33 \mathrm{AD}$ adult patients treated with placebo followed by cyclosporine $(5 \mathrm{mg} / \mathrm{kg} /$ day) or cyclosporine and then placebo for 8 weeks assessed the efficacy and safety of cyclosporine for short-term treatment [63]. In 2006, Schmitt et al. in a meta-analysis of 15 controlled and uncontrolled trials, including 602 patients with $\mathrm{AD}$, estimated a 55\% relative effectiveness [95\% confidence interval (CI) 48-62\%] for 6-8 weeks of cyclosporine therapy [59]. Several reports showed cyclosporine use in adult patients with severe $\mathrm{AD}$ either as monotherapy or in combination with antihistamines [64] or topical corticosteroids [65]. In a recent prospective, randomized 6-month study involving 60 adult patients with moderate-to-severe $\mathrm{AD}$, topical treatment combined with cyclosporine was shown to be able to reduce both the duration and cumulative dose of cyclosporine, achieving better clinical results and more prolonged disease remission [59]. In addition, a detailed analysis of drug survival for cyclosporine treatment in a long-term daily practice cohort of 356 adult AD patients with moderate-to-severe AD was performed. The median duration of cyclosporine treatment was 356 days. Two different dose regimens were used: an intermediate-to-high starting dose $(>3.5-5.0 \mathrm{mg} / \mathrm{kg} /$ day $)$ or a low starting dose $(<3.5 \mathrm{mg} / \mathrm{kg} /$ day $)$. The overall drug survival rates were $34,18,12$ and $4 \%$ after 1 , 2, 3 and 6 years, respectively. Moreover, 26.4\% patients discontinued therapy for controlled $\mathrm{AD}, 22.2 \%$ for adverse events, $16.3 \%$ for ineffectiveness and $6.2 \%$ for adverse events plus ineffectiveness. In addition, this study also demonstrated that older age and male sex were associated with decreased drug survival, whereas patients naïve to oral immunosuppressive drugs and receiving a starting dose of cyclosporine of $>3.5-5.0 \mathrm{mg} /$ $\mathrm{kg} /$ day had an increased drug survival related to ineffectiveness, meaning that discontinuation owing to ineffectiveness was decreased for patients who had an intermediate-to-high starting dose [66]. Cyclosporine remains the only approved drug for systemic treatment of adult $\mathrm{AD}$ in many countries, being usually considered as the first-line option for patients requiring immunosuppressive treatment [24].

\section{Azathioprine}

Azathioprine is a purine synthesis inhibitor that reduces leukocyte proliferation. It is used off label for treatment of severe $\mathrm{AD}$ in adults, in particular in the UK and USA [50]. Two randomized, double-blind, placebo-controlled studies (enrolling 37 and 63 subjects, respectively) [67, 68], and one single-blinded randomized controlled trial comparing 
azathioprine with methotrexate $(n=42)$ [69] showed that azathioprine was superior to placebo, with a significant clinical improvement in disease severity $(26 \%$ and $37 \%$ on clinical outcome scales after 3 months), and had a clinical efficacy equal to that of methotrexate with an expected average reduction in disease activity of about $40 \%$. Since then, several uncontrolled studies conducted in both adults and children have demonstrated similar results [70, 71]. In particular, azathioprine efficacy was tested in a retrospective uncontrolled study involving 48 children and adolescents aged 6-16 years diagnosed with severe $\mathrm{AD}$ [72]. All patients started with a dose of $2 \mathrm{mg} / \mathrm{kg}$ twice a day, and the dose was increased to $3 \mathrm{mg} / \mathrm{kg}$ twice a day in 14 patients because of insufficient clinical response. The mean time to achieve clinical response was 4 weeks. None of the patients showed myelotoxic symptoms. After 3 months of therapy, 28 patients (58.3\%) showed excellent results and 13 patients (27.1\%) showed good improvement, whereas only 7 patients (14.6\%) showed little or no improvement. In 2009, another retrospective uncontrolled study including 17 patients (mean age of $16.1 \pm 3.9$ years) with recalcitrant $\mathrm{AD}$ showed significant improvement of SCORAD after 3 months and 6 months of treatment with azathioprine as well as significant reduction in total serum IgE levels [73]. Azathioprine has an intriguing metabolism with several immunosuppressant metabolites, governed by thiopurine methyltransferase activity (TPMT), so that the azathioprine dosage should be determined based on the TPMT genotype or activity levels to limit the possible appearance of myelotoxicity. A randomized control trial showed that adult patients with AD in whom the azathioprine dose was adapted to TPMT activity had similar disease improvement compared with patients with normal TPMT activity receiving $2.5 \mathrm{mg} / \mathrm{kg}$ azathioprine [68]. Adverse events of azathioprine include gastrointestinal disturbances, liver dysfunction and leukopenia [67]. There is no definite information regarding the duration of treatment with azathioprine in adult patients with $\mathrm{AD}$, and data on long-term adherence are lacking. A 5-year retrospective study of two Danish dermatological hospital departments including 74 adult outpatients (aged $\geq 18$ years) treated with azathioprine (doses ranging between 25 and $200 \mathrm{mg}$ daily) for severe $\mathrm{AD}$ showed that after 1 year of treatment around half of the patients retained the clinical benefit and had no significant adverse effects. The other half of patients discontinued at some stage within the first year owing to a lack of clinical benefit or to adverse effects, predominantly gastrointestinal disturbances [74].

Data on azathioprine efficacy and safety in adult AD patients are sparse; it may be used (off label) when cyclosporine is either not effective or contraindicated.

\section{Methotrexate}

Methotrexate (MTX) is an antimetabolite, interfering with folic acid metabolism, that regulates the immune system and inflammatory processes. Several studies suggested that MTX is a well-tolerated and effective treatment for moderate-to-severe forms of $\mathrm{AD}$ [75-79]. However, its use in $\mathrm{AD}$ is still off label. A randomized trial with methotrexate versus azathioprine showed a comparable effect in severe atopic eczema [75]. Furthermore, a 24-week therapy with MTX (median dose $15 \mathrm{mg}$ weekly) resulted in an improvement of disease activity by $52 \%$ from baseline, with a persistent improvement in 8 of 12 patients over 12 weeks after stopping MTX [76]. An open retrospective 
study showed that $75 \%$ of patients (17-68 years old) with severe $\mathrm{AD}$ treated with $7.5-25 \mathrm{mg}$ of MTX weekly reported an improvement of $>70 \%$ of the Physician's Global Assessment (PGA) after 3 months of therapy [77]. Similar results were observed after 8-12 weeks of low-dose MTX treatment in 20 adult $\mathrm{AD}$ patients [78]. Liver and bone marrow toxicity has to be controlled before starting MTX therapy and during its course. Clinical experience reported nausea, fatigue, hepatotoxicity, hematological abnormalities, pulmonary toxicity and drug interaction as the main observed side effects commonly causing discontinuation of MTX treatment [76-78]. Recent data came from a retrospective study that reported the efficacy and safety of oral and/or subcutaneous MTX in a long-term daily practice cohort of 89 patients (aged $\geq 18$ years) with severe AD. Particularly, a maximum dose of MTX between 5 and 10 and $25 \mathrm{mg}$ once weekly was prescribed. The overall drug survival showed that 73,41 and $34 \%$ of patients still used MTX after 6 months, 1 year and 2 years, respectively, with a median treatment duration of 223 days. However, 17, 33 and 33\% of subjects discontinued MTX treatment for adverse events after 6 months, 1 and 2 years, respectively [79]. Gastrointestinal complaints, fatigue and headache were the most common adverse events reported; transient liver enzyme elevations were also observed. Therefore, even though MTX shows effective results in AD patients, its use is limited by the frequently reported side effects. Since MTX is about equally effective to azathioprine [75], its use (off label) may be recommended when cyclosporine is either not effective or contraindicated.

\section{Mycophenolic Acid/Mycophenolic Mofetil}

Mycophenolic acid (MPA) and its prodrug, named mycophenolic mofetil (MMF), is an antimetabolite that inhibits B- and T-cell proliferation. Several cases and small studies showed its efficacy when used off label in adult patients with $\mathrm{AD}$ who were unresponsive to cyclosporine therapy [51, 80]. Monotherapy with MPA in eight adult patients with severe $\mathrm{AD}$ led to a significant reduction of disease severity after 4-week therapy in five of the eight treated subjects (62.5\%) [81]. Although MPA at $2 \mathrm{~g}$ /day had a slower onset of action compared to cyclosporine in patients with $\mathrm{AD}$ [82], enteric-coated mycophenolate sodium (1440 mg/day), a different formulation of MPA created to improve MPA-related upper gastrointestinal adverse events [83], had the same efficacy as low-dose cyclosporine in $\mathrm{AD}$ maintenance treatment [58]. In 2009, van Velsen et al. published the first open-label study regarding the efficacy and safety of enteric-coated mycophenolate sodium (720 mg twice a daily for 6 months) in treating ten adult patients with recalcitrant AD [84]. Conversely, MMF was successfully used as long-term treatment (1-2 g daily over 12-29 months) in three patients with a chronic form of atopic eczema [85]. A recent retrospective study demonstrated that there was a direct correlation between UGT1A9 polymorphisms and MPA therapy unresponsiveness in patients with AD [86]. The main side effects reported during MPA therapy were nausea, fatigue, flu-like syndrome and liver enzyme alteration [80, 87, 88]. Studies supporting MPA or MMF therapy in adult AD patients are limited, so it should only be considered a possible alternative treatment when other systemic drugs fail or show side effects and/or contraindication.

\section{Alitretinoin}

Alitretinoin is a retinoid binding both retinoid and rexinoid receptors, thus resulting in antiinflammatory and antiproliferative effects [24]. It is licensed in some European countries 
for the treatment of chronic hand eczema irrespectively of its pathogenesis, so it can sometimes be used in atopic hand eczema [24]. A multicenter, randomized, placebo-controlled clinical trial involving 1032 patients with chronic hand eczema, about one-third of which were probably atopic hand eczema patients, showed improvement of eczema symptoms in $75 \%$ of cases with alitretinoin, showing better clinical outcomes in hyperkeratotic hand eczema and pulpitis sicca [89]. The administration of a standard dose of $30 \mathrm{mg}$ daily of alitretinoin for 12 weeks resulted in an improvement of palmar and extrapalmar lesions in six patients with $\mathrm{AD}$ with prominent hand involvement [90]. Moreover, there is a recent case report in which a 52-year-old male with lichen simplex chronicus and severe $\mathrm{AD}$ of the hands was successfully treated with alitretinoin at a daily dosage of $30 \mathrm{mg}$ for 3 months [91]. Treatment with alitretinoin should be considered in $\mathrm{AD}$ patients with prominent involvement of the hands, who are resistant to topical corticosteroids and calcineurin inhibitors. Headache, serum lipid and thyroid-stimulating hormone elevation were the most frequent adverse events occurring during alitretinoin therapy [89]. Moreover, since alitretinoin is teratogenic, all women of childbearing age must adhere to a strict birth control program. Overall studies supporting alitretinoin efficacy in adult $\mathrm{AD}$ patients are limited. Its use may be suggested in atopic hand eczema in adult patients unresponsive to topical steroid and tacrolimus [24].

\section{Biologics}

The development of biological therapies has rapidly progressed during the last few years. Biologic drugs are a class of pharmacological agents engineered to target specific mediators of inflammation. During the past several years, multiple clinical trials and case reports have demonstrated the efficacy of targeted therapy blocking cytokines or mediators that play a pivotal role in the pathogenesis of $\mathrm{AD}$. Although none of these biologic drugs have been approved for the treatment of adult AD so far, dupilumab has received breakthrough therapy designation and has been accepted for priority review from the US Food and Drug Administration (FDA) for the treatment of adult patients with inadequately controlled moderate-to-severe $\mathrm{AD}$, and different clinical trials are now being conducted to determine the efficacy, dosing and long-term safety of these promising therapies [92]. Biological drugs, especially dupilumab, appears to be a promising treatment for adult $\mathrm{AD}$ patients, because they offer more convenient dose regimens and less frequent laboratory monitoring than other systemic therapies as well as fewer side effects (see Table 1 for details). Future studies are needed to overcome unmet needs and to reach high and better standards of care for $\mathrm{AD}$ patients. In this context, dupilumab represents a promising drug that may have a positive and deep impact on the adult $\mathrm{AD}$ world.

\section{Rituximab}

$\mathrm{T}$ cells play a key role in the pathogenetic pathway of $\mathrm{AD}$, but $\mathrm{B}$ cells might also participate in its development. Data about rituximab, a monoclonal antibody against the protein CD20, which is primarily found on the surface of immune system B cells, used for adult $\mathrm{AD}$ patient treatment, are limited. To date, evidence for the efficacy of rituximab in treating adult patients with severe $\mathrm{AD}$ is exclusively based on case reports and series $[93,94]$. Rituximab, acting by decreasing B cells, 
was reported to be effective in reducing skin inflammation in six patients with $\mathrm{AD}$, treated with two 1000-mg intravenous infusions, 2 weeks apart [93]. All patients showed an improvement of their skin symptoms within 4-8 weeks [93]. Moreover, another study regarding two $\mathrm{AD}$ patients who received a lower dose of rituximab (two doses of $500 \mathrm{mg}$ each, 2 weeks apart), showed only limited effects [94]. One patient improved, with the SCORAD score reducing from 99 to 58 at week 10 , but the other experienced an AD worsening with the SCORAD score increasing from 63 to 74 at week 10. A further study on four patients with severe $\mathrm{AD}$ was reported [95]; patients were given a cycled therapy of omalizumab and rituximab. Particularly, all patients received an induction cycle of four IV infusions of $375 \mathrm{mg} /$ $\mathrm{m}^{2}$ rituximab, with each infusion administered weekly, and four out of six patients received a maintenance cycle of two infusions of $1 \mathrm{~g}$ rituximab administered every 2 weeks. No objective assessment of the disease was reported, but some patients improved and some had long-lasting benefits. On the other hand, another study reported the failure of rituximab in three adult patients with severe AD. Patients did not report major change in the pre- and post- treatment Eczema Area Severity Index. The pre-treatment Eczema Area Severity Index (EASI) values were 34, 64.4 and 42.2 compared with the post-treatment values of 32.2, 66 and 56.4, respectively [96]. No adverse events were reported. Data regarding rituximab efficacy in adult AD are controversial. Further studies are needed to support its use in this class of patients.

\section{Ustekinumab}

Ustekinumab is a fully human immunoglobulin G1 (IgG1) monoclonal antibody that binds with high specificity to the p40 subunit of IL-12 and
IL-23, two cytokines that are thought to play a key role in the development of immune-mediated inflammatory diseases. Indeed, they are involved in promoting the development and proliferation of Th17 and Th22 $\mathrm{T}$ cells as well as the differentiation of naive $\mathrm{T}$ cells into Th1 cells. Therefore, ustekinumab may be useful in $\mathrm{AD}$, which is increasingly recognized as a Th2- and Th22-centered disease with some contributions of the Th17 and Th1 axes [97]. However, evidence of ustekinumab efficacy in adult $\mathrm{AD}$ is controversial and mainly based on case reports or small case series. Particularly, Puya et al. reported the case of a 21-year-old female with severe $\mathrm{AD}$ refractory to systemic immunosuppressive treatment who underwent a 12-month therapy with ustekinumab with complete resolution of skin lesions and their related symptoms such as itching [98]. Similar results were observed by Shroff et al. who reported a decrease of SCORAD from 50 to 0 after 19 weeks of treatment in a 70-year-old female with severe $\mathrm{AD}$ as well as by Fernández-Antón Martínez et al. in four adult patients with severe AD (mean SCORAD decreased from 77.8 to 20.2 at 16 weeks of therapy) [99, 100]. Moreover, recently, Weiss et al. related that ustekinumab was able to achieve a 50\% reduction in the EASI Index score by week 16 in three adult $\mathrm{AD}$ patients together with a decrease in the degree of epidermal hyperplasia/proliferation, the number of infiltrating dermal $\mathrm{T}$ cells, dendritic cells and mast cells as well as in T-helper 2-/22-associated molecules [101]. In all these studies, ustekinumab (45 mg) was administered following the established protocol for psoriasis, despite patient weight. On the other hand, a recent phase II, double-blind, placebo-controlled study with 33 patients with moderate-to-severe $\mathrm{AD}$ randomly assigned to 
either ustekinumab $(n=16)$ or placebo $(n=17)$, with subsequent crossover at 16 weeks, and the last dose at 32 weeks, showed that the ustekinumab group achieved higher SCORAD50 responses at 12, 16 and 20 weeks compared to placebo, however without approaching statistical significance [102]. In this trial, dosing of ustekinumab followed the recommendations for psoriasis, namely 45 and $90 \mathrm{mg}$ per injection for patients weighing $\leq 100$ or $>100 \mathrm{~kg}$, respectively, and the authors also observed that ustekinumab could determine a significant modulation of Th1, Th17 and Th22 and Th2-related AD genes after 4 weeks of treatment (i.e., MMP12, IL-22, IL-13, IFN- $\gamma$, elafin/PI3, CXCL1, CCL17) [102]. In addition, other authors reported inadequate response to ustekinumab treatment in two adult $\mathrm{AD}$ patients even if with the addition of aggressive topical corticosteroid therapy, whereas Lis-Święty et al. observed an exacerbation of AD under ustekinumab therapy in a psoriatic patient with a childhood history of atopy $[103,104]$. In summary, data regarding ustekinumab efficacy in adult $\mathrm{AD}$ are controversial and scant, with the only existing double-blind placebo-controlled study lacking evidence of statistically significant efficacy. Further studies are needed to investigate its role in adult $\mathrm{AD}$ treatment.

\section{Omalizumab}

Omalizumab is a recombinant, humanized monoclonal antibody against the high-affinity Fc receptor of human IgE (FceRI), which is administered subcutaneously. The US FDA has approved this drug for severe allergic asthma and chronic spontaneous urticaria treatment [105]. Since AD may share a common pathologic mechanism with asthma (high $\operatorname{IgE}$ levels in blood), omalizumab has been also used to treat patients with severe forms of $\mathrm{AD}$ associated with high IgE blood levels [106-108], reporting a significant efficacy in improving AD-related quality of life scores [109]. Omalizumab induces lymphocyte polarization toward a type 2 immune response and quenches eosinophil-mediated inflammation [110]. Currently available data on $\mathrm{AD}$ treatment with omalizumab are controversial [111-129]. Efficacy of off-label omalizumab use in adult AD patients is only supported by case reports or small case series involving a total of 39 subjects [111-119]. Most of these studies showed only partial efficacy. Particularly, in 2005, Fernandez Anton-Martinez et al. described their experience in nine adult patients (aged between 26 and 42 years) with severe $A D$, in whom $450 \mathrm{mg}$ of omalizumab every 3 weeks achieved an improvement in quality of life and decreased pruritus in $7 / 9$ patients [115]. In addition, Forman and Garrett reported the case of a 41-year-old black male with severe $\mathrm{AD}$, which previously had only responded to oral corticosteroids, that was successfully treated with a 12-week course of omalizumab [116]. However, Belloni et al. reported that low-dose omalizumab therapy (10 cycles of $150 \mathrm{mg}$ subcutaneously at 2-week intervals) was able to decrease SCORAD levels by more than $50 \%$ in only $2 / 11(18.2 \%)$ subjects and by $25-50 \%$ in $4 / 11(36.4 \%)$ AD patients [117]. Similar results have been recently reported by Holm et al., who observed good or some effects in disease improvement (through SCORAD scores) in only 4/9 (44.5\%) adult AD patients treated with omalizumab [118]. Conversely, more significant results in limiting AD skin symptoms have been reported in patients with concomitant $\mathrm{AD}$ and bronchial asthma by small case series involving almost 40 subjects [120-124]. For example, Kim et al. reported that $7 / 10(70 \%)$ of patients with $\mathrm{AD}$ who 
received omalizumab for persistent asthma experienced improvement in SCORAD scores; however, no placebo group was included in the study [123]. Moreover, a prospective analysis including 21 patients (14-64 years old) with moderate-to-severe persistent allergic asthma and $\mathrm{AD}$ showed a statistically significant clinical improvement of $\mathrm{AD}$ in all patients [124]. Moreover, Zink et al. found a relationship between reduction in free $\operatorname{IgE}$ levels and $\mathrm{AD}$ clinical improvement by combining extracorporeal immunoadsorption and omalizumab therapy in ten patients with severe and therapy-refractory AD [125], whereas Toledo et al. showed the beneficial effects of the association of intravenous immunoglobulins with omalizumab and reported good results in 3/4 AD cases with concomitant asthma [126]. On the other hand, Hotze et al. observed no effects or worsening in $12 / 20(60 \%)$ subjects conducting a prospective 28-week open-label trial on 20 adults with moderate-to-severe $\mathrm{AD}$ treated with omalizumab, hypothesizing that only the subgroups of $\mathrm{AD}$ patients without filaggrin mutations may benefit from this treatment [127]. Omalizumab ineffectiveness in adult $\mathrm{AD}$ patients is also supported by other studies [128, 129]. Particularly, a randomized, placebo-controlled, double-blind study including 20 adult $\mathrm{AD}$ patients treated with omalizumab (0016 mg/kg/IgE) for 16 weeks reported no significant improvement in clinical signs of $\mathrm{AD}$ despite great changes in IgE levels (reduced free serum IgE, surface IgE and Fc\&RI expression; lowered number of IgE+, but not of FceRI+ cells in the skin) [128]. Moreover, Krathen and Shu described their experience with three adult patients with severe AD treated with omalizumab (450 mg every 2 weeks for 4 months) achieving no clinical response (no improvement in chronic lichenified eczema or reduction in symptomatic flares of the disease) [129]. The most commonly reported side effects of omalizumab are mild and include local reaction at the injection site and increased risk of infections and headache; anaphylaxis is rare, and there is no demonstrated carcinogenesis risk $[115,118,119,128]$. Data on omalizumab efficacy in adult $\mathrm{AD}$ are controversial. The only existing randomized, placebo-controlled, double-blind study failed to show its efficacy. Based on small case series in the existing literature, omalizumab may be useful for the treatment of severe $\mathrm{AD}$ refractory to topical and systemic treatments, especially in patients with concomitant asthma and without filaggrin mutations.

\section{Dupilumab}

Dupilumab is a fully human monoclonal antibody that targets IL-4 receptor- $\alpha$ and inhibits signaling of IL-4 and IL-13, key Th2 cytokines that play an important role in $\mathrm{AD}$ development [130-133]. Several clinical trials showed that treatment with dupilumab, subcutaneously administered, resulted in significant symptomatic and clinical improvement in adult patients with moderate-to-severe AD [130, 134-140]. The clinical benefit was supported by the improvement in the serum levels of Th2-associated biomarkers, such as thymus and activation-regulated chemokine (TARC), total IgE and eosinophil counts [136] and by the improvement of the AD molecular signature tested with transcriptomic analyses of pre- and post-treatment skin biopsy specimens from patients with moderate-to-severe $\mathrm{AD}$ treated weekly with 150 or $300 \mathrm{mg}$ dupilumab [137]. The best data supporting its efficacy and safety came from two randomized, placebo-controlled, phase 3 trials (SOLO1 and SOLO2), involving 671 and 708 adult patients 
( $>18$ years of age) with moderate-to-severe $\mathrm{AD}$, respectively [137]. Patients were randomly assigned in a 1:1:1 ratio to receive 16 weeks of weekly subcutaneous injections of dupilumab (300 $\mathrm{mg}$ ) or placebo or the same dose of dupilumab every other week alternating with placebo. Patients in the dupilumab groups received a $600-\mathrm{mg}$ loading dose of dupilumab on day 1. In SOLO 1, 85 patients (38\%) who received dupilumab every other week, 83 (37\%) who received dupilumab weekly and 23 (10\%) who received placebo had a score of 0 or 1 (clear or almost clear) on the Investigator's Global Assessment (IGA). Conversely, in SOLO 2, 84 patients (36\%) who received dupilumab every other week, 87 (36\%) who received dupilumab weekly and 20 (8\%) who received placebo had a score of 0 or 1 . Furthermore, a randomized placebo-controlled, dose-ranging phase $2 \mathrm{~b}$ trial evaluated 380 patients (aged $\geq 18$ years) with moderate-to-severe $\mathrm{AD}$ who were treated with dupilumab at five different dose regimens (300 mg once a week, $300 \mathrm{mg}$ every 2 weeks, $200 \mathrm{mg}$ every 2 weeks, $300 \mathrm{mg}$ every 4 weeks, $100 \mathrm{mg}$ every 4 weeks or placebo once a week) for 16 weeks [138]. All major objective clinical measures such as the as EASI, IGA and SCORAD scores were measured for every patient treated with dupilumab, resulting in a dose-dependent efficacy. The most consistent benefits were obtained with dose regimens of $300 \mathrm{mg}$ once a week and $300 \mathrm{mg}$ every 2 weeks. By week 16, $82.5 \%$ of patients achieved EASI-50, $60.3 \%$ achieved EASI-75 and 36.5\% achieved EASI-90 in patients given $300 \mathrm{mg}$ dupilumab once a week compared with 29.5, 11.5 and $3.3 \%$ of patients in the placebo group [138]. Dupilumab was well tolerated, and no dose-limiting toxic effects were recorded. Moreover, the authors complemented this clinical trial with other analyses, also showing dupilumab's efficacy in relation to patients' mental and physical functioning by evaluating clinical improvements in itching, sleep, mental health and overall health status after 1 week of treatment [139, 140]. Particularly patients treated with dupilumab had rapid improvement not only in skin lesions, but also a rapid reduction in pruritus, which is a major contributor to the reduced quality of life experienced by patients with AD. Previously, a 12-week randomized, double-blind, placebo-controlled phase $2 \mathrm{a}$ study regarding dupilumab therapy in 109 adult patients with moderate-to-severe $\mathrm{AD}$ had demonstrated consistent results: EASI-50 was achieved by $85 \%$ of subjects and EASI-75 by $62 \%$ of patients given $300 \mathrm{mg}$ dupilumab once a week compared with $35 \%$ and $15 \%$, respectively, of the placebo group [130]. In all clinical studies to date, dupilumab has shown a favorable safety profile with no dose-limiting toxicity and few adverse effects [141-143]. These include nasopharyngitis, upper respiratory tract infections, headache, injection-site reaction and back pain [130, 141-143]. Due to these promising results, dupilumab has the potential to become the first biological systemic therapy for $\mathrm{AD}$ treatment in adult patients unresponsive to topical corticosteroids or topical calcineurin inhibitors [143]. Recently, it received the US FDA breakthrough therapy designation for $\mathrm{AD}$, with ongoing trials in both adult and pediatric populations [143]. For all these reasons, dupilumab will probably completely change the treatment opportunities for severe adult $\mathrm{AD}$ in the following years, presenting the most efficacious and safe systemic treatments for these patients.

\section{Small Molecules}

Small molecules are able to modulate proinflammatory cytokines, through selective target of signaling pathways and molecules 
inside immune cells, showing potential to treat inflammatory diseases in patients not responding to conventional treatments [144]. Among small molecules, only phosphodiesterase 4 inhibitors have been used off label to treat severe and recalcitrant $\mathrm{AD}$, presenting new interesting and promising treatment options for the unmet treatment needs of adult $\mathrm{AD}$ patients.

\section{Apremilast}

Apremilast is a novel oral agent that modulates multiple antiinflammatory pathways targeting phosphodiesterase type IV (PDE4) inhibition. It has been studied for the treatment of asthma, chronic obstructive pulmonary disease, psoriasis and psoriatic arthritis (PsA) [145]. In 2014, apremilast was approved by the US FDA for the treatment of active PsA in adults and of moderate-to-severe plaque psoriasis in patients who are candidates for phototherapy or systemic therapy [146]. Literature data investigating the role of apremilast in treating recalcitrant forms of adult $\mathrm{AD}$ are limited. In 2014, an open-label pilot study involving 16 adult patients (age $\geq 18$ years) with moderate-to-severe $\mathrm{AD}$ who were treated with apremilast was performed [147]. Particularly, six patients received $20 \mathrm{mg}$ twice daily for 3 months (Cohort1), while the other ten patients received apremilast $30 \mathrm{mg}$ twice daily for a total of 6 months (Cohort2). This treatment resulted in a significant reduction of the EASI score with an average of $19 \%$ in Cohort 1 and $39 \%$ in Cohort 2 at 3 months [147]. Nausea was the most common side effect followed by diarrhea and headache; an episode of herpes zoster during the treatment period was reported [147]. Previously, a phase 2, open-label, investigator-initiated study reported the safety and efficacy of apremilast ( $20 \mathrm{mg}$ twice daily for 12 weeks) in ten patients with either $\mathrm{AD}$ and/or allergic contact dermatitis. Ten percent of patients achieved EASI-75, whereas another $10 \%$ achieved EASI-50; 20\% had an improvement by two or more points of IGA [148]. To date, limited data are available for apremilast use in AD patients. Even though apremilast has been shown to be an interesting and promising drug, especially due to its safety profile, further studies are needed to clearly assess its efficacy in the treatment of moderate-to-severe recalcitrant adult AD.

\section{CONCLUSION}

Data for the long-term safety and comparative effectiveness of different systemic immunosuppressive therapies in adult $\mathrm{AD}$ patients are insufficient. Therefore, large variations exist in systemic treatment approaches to adult $\mathrm{AD}$ worldwide, and international standardized guidelines are lacking. Cyclosporine is the only approved drug for systemic treatment of adult $\mathrm{AD}$, being usually considered as the first-line option for patients requiring immunosuppressive treatment. A biologic drug such as dupilumab, which has recently received the US FDA breakthrough therapy designation for $\mathrm{AD}$, presents as the most efficacious and safe systemic treatment for adult $\mathrm{AD}$ patients and will probably completely change the $\mathrm{AD}$ scenario in the next years. Further studies are needed to develop shared international guidelines.

\section{ACKNOWLEDGEMENTS}

No funding or sponsorship was received for this study or publication of this article. All named authors meet the International Committee of 
Medical Journal Editors (ICMJE) criteria for authorship for this manuscript, take responsibility for the integrity of the work as a whole and have given final approval for the version to be published.

Disclosures. Matteo Megna, Maddalena Napolitano, Cataldo Patruno, Alessia Villani, Anna Balato, Giuseppe Monfrecola, Fabio Ayala and Nicola Balato have nothing to disclose.

Compliance with Ethics Guidelines. This article is based on previously conducted studies and does not involve any new studies of human or animal subjects performed by any of the authors.

Open Access. This article is distributed under the terms of the Creative Commons Attribution-NonCommercial 4.0 International License (http://creativecommons.org/licenses/ by-nc/4.0/), which permits any noncommercial use, distribution, and reproduction in any medium, provided you give appropriate credit to the original author(s) and the source, provide a link to the Creative Commons license, and indicate if changes were made.

\section{REFERENCES}

1. Garritsen FM, Roekevisch E, van der Schaft J, Deinum J, Spuls PI, de Bruin-Weller MS. Ten years experience with oral immunosuppressive treatment in adult patients with atopic dermatitis in two academic centres. J Eur Acad Dermatol Venereol. 2015;29:1905-12.

2. Silverberg JI, Hanifin JM. Adult eczema prevalence and associations with asthma and other health and demographic factors: a US population-based study. J Allergy Clin Immunol. 2013;132:1132-8.

3. Garmhausen D, Hagemann T, Bieber T, et al. Characterization of different courses of atopic dermatitis in adolescent and adult patients. Allergy. 2013;68:498-506.
4. Napolitano M, Megna M, Patruno C, Gisondi P, Ayala F, Balato N. Adult atopic dermatitis: a review. G Ital Dermatol Venereol. 2016;151:403-11.

5. Bieber T. Atopic dermatitis. $N$ Engl J Med. 2008;358:1483-94.

6. Katsarou A, Armenaka M. Atopic dermatitis in older patients: particular points. J Eur Acad Dermatol Venereol. 2011;25:12-8.

7. Illi S, von Mutius E, Lau S, et al. Multicenter Allergy Study Group. The natural course of atopic dermatitis from birth to age 7 years and the association with asthma. J Allergy Clin Immunol. 2004;113:925-31.

8. Williams HC, Strachan DP. The natural history of childhood eczema: observations from the British 1958 birth cohort study. Br J Dermatol. 1998;139:834-9.

9. Wüthrich B. Clinical aspects, epidemiology, and prognosis of atopic dermatitis. Ann Allergy Asthma Immunol. 1999;83:464-70.

10. Schmitt J, Schmitt NM, Kirch W, Meurer M. Outpatient care and medical treatment of children and adults with atopic eczema. J Dtsch DermatGes. 2009;7:345-51.

11. Su VY, Chen TJ, Yeh CM, et al. Atopic dermatitis and risk of ischemic stroke: a nationwide population-based study. Ann Med. 2014;46:84-9.

12. Silverberg JI. Association between adult atopic dermatitis, cardiovascular disease, and increased heart attacks in three population-based studies. Allergy. 2015;70:1300-8.

13. Silverberg JI, Silverberg NB, Lee-Wong M. Association between atopic dermatitis and obesity in adulthood. Br J Dermatol. 2012;166:498-504.

14. Zhang A, Silverberg JI. Association of atopic dermatitis with being overweight and obese: a systematic review and metaanalysis. J Am Acad Dermatol. 2015;72:606-16.

15. Balato N, Patrì A, Napolitano M, Megna M, Patruno C. What's new about atopic dermatitis and sporting activity. G Ital Dermatol Venereol. 2016;151:219-20.

16. Werfel T, Schwerk N, Hansen G, Kapp A. The diagnosis and graded therapy of atopic dermatitis. Dtsch Arztebl Int. 2014;111:509-20.

17. Simon D. Systemic therapy of atopic dermatitis in children and adults. Curr Probl Dermatol. 2011;41:156-64. 
18. Védie AL, Ezzedine K, Amazan E, et al. Long-term use of systemic treatments for moderate-to-severe atopic dermatitis in adults: a monocentric retrospective study. Acta Derm Venereol. 2016;96:802-6.

19. Deleuran MS, Vestergaard C. Therapy of severe atopic dermatitis in adults. J Dtsch Dermatol Ges. 2012;10:399-406.

20. Saeki H, Furue M, Furukawa F, et al. Committee for guidelines for the management of atopic dermatitis of Japanese dermatological association. Guidelines for management of atopic dermatitis. J Dermatol. 2009;36:563-77.

21. Roekevisch E, Spuls PI, Kuester D, Limpens J, Schmitt J. Efficacy and safety of systemic treatments for moderate-to-severe atopic dermatitis: a systematic review. J Allergy Clin Immunol. 2014;133:429-38.

22. Werner-Busse A, Kostev K, Heine G, Worm M. Impact of comorbidities on the treatment of atopic dermatitis in clinical practice. Int J Clin Pharmacol Ther. 2014;52:726-31.

23. Oranje AP. Evidence-based pharmacological treatment of atopic dermatitis: an expert opinion and new expectations. Indian $J$ Dermatol. 2014;59:140-2.

24. Ring J, Alomar A, Bieber T, et al. Guidelines for treatment of atopic eczema (atopic dermatitis) Part II. J Eur Acad Dermatol Venereol. 2012;26:1176-93.

25. Patrizi A, Raone B, Ravaioli GM. Management of atopic dermatitis: safety and efficacy of phototherapy. Clin Cosmet Investig Dermatol. 2015;8:511-20.

26. Kamata Y, Tominaga M, Takamori K. Itch in atopic dermatitis management. Curr Probl Dermatol. 2016;50:86-93.

27. Chan IH, Murrell DF. Itch management: physical approaches (UV phototherapy, acupuncture). Curr Probl Dermatol. 2016;50:54-63.

28. El Samahy MH, Attia EA, Saad AA, Mahmoud EY. Circulating CD4(+) CD25(high) FoxP3(+) T-regulatory cells in patients with atopic dermatitis after narrowband-ultraviolet B phototherapy. Int J Dermatol. 2015;54:424-9.

29. Holme SA, Anstey AV. Phototherapy and PUVA photochemotherapy in children. Photodermatol Photoimmunol Photomed. 2004;20:69-75.

30. Dogra S, Mahajan R; Indian Association of Dermatologists, Venereologists and Leprologists.
Phototherapy for atopic dermatitis. Indian J Dermatol Venereol Leprol. 2015;81:10-5.

31. Garritsen FM, Brouwer MW, Limpens J, Spuls PI. Photo(chemo)therapy in the management of atopic dermatitis: an updated systematic review with implications for practice and research. $\mathrm{Br} \mathrm{J}$ Dermatol. 2014;170:501-13.

32. Kowalzick L, Kleinheinz A, Weichenthal M, Neuber K, Köhler I, Grosch J, Lungwitz G, Seegeberg C, Ring J. Low dose versus medium dose UV-A1 treatment in severe atopic eczema. Acta Derm Venereol. $1995 ; 75: 43-5$.

33. Tzaneva S, Seeber A, Schwaiger M, Hönigsmann $H$, Tanew A. High-dose versus medium-dose UVA1 phototherapy for patients with severe generalized atopic dermatitis. J Am Acad Dermatol. 2001;45:503-7.

34. George SA, Bilsland DJ, Johnson BE, Ferguson J. Narrow-band (TL-01) UVBair-conditioned phototherapy for chronic severe adult atopic dermatitis. Br J Dermatol. 1993;128:49-56.

35. Rodenbeck DL, Silverberg JI, Silverberg NB. Phototherapy for atopic dermatitis. Clin Dermatol. 2016;34:607-13.

36. Bogaczewicz J, Malinowska K, Sysa-Jedrzejowska A, Wozniacka A. Medium dose ultraviolet al phototherapy and mRNA expression of interleukin 8 , interferon $\gamma$, and chemokine receptor 4 in acute skin lesions in atopic dermatitis. Postepy Dermatol Alergol. 2016;33:170-5.

37. Attili SK, Dawe RS, Ibbotson SH. Ultraviolet A1 phototherapy: One center's experience. Indian J Dermatol Venereol Leprol. 2016.

38. Krutmann J, Diepgen TL, Luger TA, Grabbe S, Meffert H, Sönnichsen N, Czech W, Kapp A, Stege H, Grewe M, Schöpf E. High-dose UVA1 therapy for atopic dermatitis: results of a multicenter trial. J Am Acad Dermatol. 1998;38:589-93.

39. Krutmann J, Czech W, Diepgen T, Niedner R, Kapp A, Schöpf E. High-dose UVA1 therapy in the treatment of patients with atopic dermatitis. J Am Acad Dermatol. 1992;26:225-30.

40. Abeck D, Schmidt T, Fesq H, Strom K, Mempel M, Brockow K, Ring J. Long-term efficacy of medium-dose UVA1 phototherapy in atopic dermatitis. J Am Acad Dermatol. 2000;42:254-7.

41. Napolitano M, Megna M, Balato A, et al. Systemic treatment of pediatric psoriasis: a review. Dermatol Ther (Heidelb). 2016;6:125-42.

42. Fernández-Guarino $\mathrm{M}$, Aboin-Gonzalez S, Barchino L, Velazquez D, Arsuaga C, Lázaro P. Treatment of 
moderate and severe adult chronic atopic dermatitis with narrow-band UVB and the combination of narrow-band UVB/UVA phototherapy. Dermatol Ther. 2016;29:19-23.

43. Gambichler T, Othlinghaus N, Tomi NS, et al. Medium-dose ultraviolet (UV) A1 vs. narrowband UVB phototherapy in atopic eczema: a randomized crossover study. Br J Dermatol. 2009;160:652-65.

44. Majoie IM, Oldhoff JM, van Weelden $H$, Laaper-Ertmann M, Bousema MT, Sigurdsson V, Knol EF, Bruijnzeel-Koomen CA, de Bruin-Weller MS. Narrowband ultraviolet B and medium-dose ultraviolet al are equally effective in the treatment of moderate to severe atopic dermatitis. J Am Acad Dermatol. 2009;60:77-84.

45. Ring J, Alomar A, Bieber T, et al. Guidelines for treatment of atopic eczema (atopic dermatitis) part I. J Eur Acad Dermatol Venereol. 2012;26:1045-60.

46. Tzaneva S, Kittler H, Holzer G, Reljic D, Weber M, Hönigsmann H, Tanew A. 5-Methoxypsoralen plus ultraviolet (UV) A is superior to medium-dose UVA1 in the treatment of severe atopic dermatitis: a randomized crossover trial. $\mathrm{Br} \mathrm{J}$ Dermatol. 2010;162:655-60.

47. Uetsu N, Horio T. Treatment of persistent severe atopic dermatitis in 113Japanese patients with oral psoralen photo-chemotherapy. J Dermatol. 2003;30:450-7.

48. Der-Petrossian M, Seeber A, Hönigsmann H, Tanew A. Half-side comparison study on the efficacy of 8-methoxypsoralen bath-PUVA versus narrow-band ultraviolet $\mathrm{B}$ phototherapy in patients with severe chronic atopic dermatitis. $\mathrm{Br} \mathrm{J}$ Dermatol. 2000;142:39-43.

49. de Kort WJ, van Weelden H. Bath psoralen-ultraviolet A therapy in atopic eczema. J Eur Acad Dermatol Venereol. 2000;14:172-4.

50. Simon B, Bieber T. Systemic therapy for atopic dermatitis. Allergy. 2014;69:46-55.

51. Sidbury R, Tom WL, Bergman JN, et al. Guidelines of care for the management of atopic dermatitis: section 4. Prevention of disease flares and use of adjunctive therapies and approaches. J Am Acad Dermatol. 2014;71:1218-33.

52. Werfel T, Aberer W, Augustin $M$, et al. Neurodermitis: s2-guidelines. J Dtsch Dermatol Ges. 2009;7:1-46.

53. Schmitt J, Schäkel K, Fölster-Holst R, et al. Prednisolone vs. ciclosporin for severe adult eczema. An investigator-initiated double-blind placebo-controlled multicentre trial. $\mathrm{Br} J$ Dermatol. 2010;162:661-8.

54. Garnacho-Saucedo G, Salido-Vallejo R, Moreno-Giménez JC. Atopic dermatitis: update and proposed management algorithm. Actas Dermosifiliogr. 2013;104:4-16.

55. Forte WC, Sumita JM, Rodrigues AG, Liuson D, Tanaka E. Rebound phenomenon to systemic corticosteroid in atopic dermatitis. Allergol Immunopathol (Madr). 2005;33:307-11.

56. Hello M, Aubert H, Bernier C, Néel A, Barbarot S. Atopic dermatitis of the adult. Rev Med Interne. 2016;37:91-9.

57. Kim JE, Kim HJ, Lew BL, et al. Consensus guidelines for the treatment of atopic dermatitis in Korea (Part II): systemic treatment. Ann Dermatol. 2015;27:578-92.

58. Haeck IM, Knol MJ, Ten Berge O, van Velsen SG, de Bruin-Weller MS, Bruijnzeel-Koomen CA. Enteric-coated mycophenolate sodium versus cyclosporin A as long-term treatment in adult patients with severe atopic dermatitis: a randomized controlled trial. J Am Acad Dermatol 2011;64:1074-84.

59. Schmitt J, Schmitt N, Meurer M. Cyclosporin in the treatment of patients with atopic eczema-a systematic review and meta-analysis. J Eur Acad Dermatol Venereol. 2007;21:606-19.

60. Kirby B, Owen CM, Blewitt RW, Yates VM. Cutaneous $\mathrm{T}$ cell lymphoma developing in a patient on cyclosporine therapy. J Am Acad Dermatol. 2002;47:S165-7.

61. Sinha A, Velangi S, Natarajan S. Non-Hodgkin's lymphoma following treatment of atopic eczema with cyclosporine A. Acta Derm Venereol. 2004;84:327-8.

62. Laube S, Stephens M, Smith AG, Whittaker SJ, Tan BB. Lymphomatoid papulosis in a patient with atopic eczema on long-term cyclosporine therapy. Br J Dermatol. 2005;152:1346-8.

63. Sowden JM, Berth-Jones J, Ross JS, et al. Double-blind, controlled, crossover study of cyclosporin in adults with severe refractory atopic dermatitis. Lancet. 1991;338:137-40.

64. Ohtsuka T. Different effect of oral cyclosporine therapy and oral antihistamine therapy on serum high-sensitivity C-reactive protein level and thymus and activation-regulated chemokine level in atopic dermatitis in older children and adulthood. Int $J$ Dermatol. 2015;54:648-55. 
65. Kim JE, Shin JM, Ko JY, Ro YS. Importance of concomitant topical therapy in moderate-to-severe atopic dermatitis treated with cyclosporine. Dermatol Ther. 2016;29:120-5.

66. van der Schaft J, Politiek K, van den Reek JM, et al. Drug survival for ciclosporin A in a long-term daily practice cohort of adult patients with atopic dermatitis. Br J Dermatol. 2015;172:1621-7.

67. Berth-Jones J, Takwale A, Tan E, Barclay G, Agarwal $S$, Ahmed I, et al. Azathioprine in severe adult atopic dermatitis: a double-blind, placebo-controlled, crossover trial. Br J Dermatol 2002;147:324-30.

68. Meggitt SJ, Gray JC, Reynolds NJ. Azathioprine dosed by thiopurine methyltransferase activity for moderate-to-severe atopic eczema: a double-blind, randomized controlled trial. Lancet. 2006;367:839-46.

69. Schram ME, Borgonjen RJ, Bik CM, van der Schroeff JG, van Everdingen JJ, Spuls PI. Off-label use of azathioprine in dermatology: a systematic review. Arch Dermatol. 2011;147:474-88.

70. Kuanprasert N, Herbert O, Barnetson RS. Clinical improvement and significant reduction of total serum IgE in patients suffering from severe atopic dermatitis treated with oral azathioprine. Australas J Dermatol. 2002;43:125-7.

71. Hughes R, Collins P, Rogers S. Further experience of using azathioprine in the treatment of severe atopic dermatitis. Clin Exp Dermatol. 2008;33:710-1.

72. Murphy LA, Atherton D. A retrospective evaluation of azathioprine in severe childhood atopic eczema using thiopurine methlytransferase levels to exclude patients at high risk of myelosuppression. Br J Dermatol. 2002;147:308-15.

73. Hon KL, Ching GK, Leung TF, Chow CM, Lee KK, $\mathrm{Ng}$ PC. Efficacy and tolerability at 3 and 6 months following use of azathioprine for recalcitrant atopic dermatitis in children and young adults. J Dermatolog Treat. 2009;20:141-5.

74. Thomsen SF, Karlsmark T, Kk Clemmensen, et al. Outcome of treatment with azathioprine in severe atopic dermatitis: a 5-year retrospective study of adult outpatients. Br J Dermatol. 2015;172:1122-4.

75. Schram ME, Roekevisch E, Leeflang MMG, Boos JD, Schmitt J. SpulsPI. A randomized trial of methotrexate versus azathioprine for severe atopic eczema. J Allergy Clin Immunol. 2011;128:353-9.

76. Weatherhead SC, Wahie S, Reynolds NJ, Meggitt SJ. An open-label, dose-ranging study of methotrexate for moderate-to-severe adult atopic eczema. Br J Dermatol. 2007;156:346-51.

77. Goujon C, Bérard F, Dahel K, et al. Methotrexate for the treatment of adult atopic dermatitis. Eur J Dermatol. 2006;16:155-8.

78. Lyakhovitsky A, Barzilai A, Heyman R, Baum S, Amichai B, Solomon M, Shpiro D, Trau H. Low-dose methotrexate treatment for moderate-to-severe atopic dermatitis in adults. J Eur Acad Dermatol Venereol. 2010;24:43-9.

79. Politiek K, van der Schaft J, Coenraads PJ, de Bruin-Weller MS, Schuttelaar ML. Drug survival for methotrexate in a daily practice cohort of adult patients with severe atopic dermatitis. $\mathrm{Br} \mathrm{J}$ Dermatol. 2016;174:201-3.

80. Grundmann-Kollmann M, Podda M, Ochsendorf F, Boehncke WH, Kaufmann R, Zollner TM. Mycophenolate mofetil is effective in the treatment of atopic dermatitis. Arch Dermatol. 2001;137:870-3.

81. Ballester I, Silvestre JF, Pérez-Crespo M, Lucas A. Severe adult atopic dermatitis: treatment with mycophenolate mofetil in 8 patients. Actas Dermosifiliogr. 2009;100:883-7.

82. Wollenberg A, Oranje A, Deleuran M, et al. ETFAD/ EADV Eczema task force 2015 position paper on diagnosis and treatment of atopic dermatitis in adult and paediatric patients. J Eur Acad Dermatol Venereol. 2016;30:729-47.

83. Sollinger HW. Enteric coated mycophenolate sodium- current and future use in transplant patients. Expert Rev Clin Immunol. 2005;1:203-11.

84. van Velsen SG, Haeck IM, Bruijnzell-Koomen CA, de Bruin-Weller MS. First experience with enteric-coated mycophenolate sodium (Myfortic) in severe recalcitrant adult atopic dermatitis: an open label study. Br J Dermatol. 2009;160:687-91.

85. Benez A, Fierlbeck G. Successful long-term treatment of severe atopic dermatitis with mycophenolate mofetil. Br J Dermatol. 2001;144:638-9.

86. Thijs JL, Van Der Geest BA, Van Der Schaft J, et al. Predicting therapy response to mycophenolic acid using UGT1A9 genotyping: towards personalized medicine in atopic dermatitis. J Dermatolog Treat. 2016;13:1-4.

87. Balal M, Demir E, Paydas S, et al. Uncommon side effect of MMF in renal transplant recipients. Ren Fail. 2005;27:591-4.

88. Nguyen RH, Cruz PD Jr. Hepatitis due to mycophenolate mofetil used to treat atopic 
dermatitis and allergic contact dermatitis. Dermatitis. 2014;25:284-5.

89. Ruzicka T, Lynde CW, Jemec GB, et al. Efficacy and safety of oral alitretinoin (9-cis retinoic acid) in patients with severe chronic hand eczema refractory to topical corticosteroids: results of a randomized, double-blind, placebo-controlled, multicentre trial. Br J Dermatol. 2008;158:808-17.

90. Grahovac M, Molin S, Prinz JC, Ruzicka T, Wollenberg A. Treatment of atopic eczema with oral alitretinoin. Br J Dermatol. 2010;162:217-8.

91. D'Erme AM, Milanesi N, Agnoletti AF, Maio V, Massi D, Gola M. Efficacy of treatment with oral alitretinoin in patient suffering from lichen simplex chronicus and severe atopic dermatitis of hands. Dermatol Ther. 2014;27:21-3.

92. Gooderham M, Lynde CW, Papp K, et al. Review of systemic treatment options for adult atopic dermatitis. J Cutan Med Surg. 2016. doi:10.1177/ 1203475416670364 [Epub ahead of print].

93. Simon D, Hosli S, Kostylina G, et al. Anti-CD20 (rituximab) treatment improves atopic eczema. J Allergy Clin Immunol. 2008;121:122.

94. Sedivá A, Kayserová J, Vernerová E, et al. Anti-CD20 (rituximab) treatment for atopic eczema. J Allergy Clin Immunol. 2008;121:1515-6.

95. Sanchez-Ramon S, Equiluz-Garcia I, Rodriquez-Mazariego ME, et al. Sequential combined therapy with omalizumab and rituximab: a new approach to severe atopic dermatitis. J Investig Allergol Clin Immunol. 2013;23:190-6.

96. Mc Donald BS, Jones J, Rustin M. Rituximab as a treatment for severe atopic eczema: failure to improve in three consecutive patients. Clin Exp Dermatol. 2016;41:45-7.

97. Nograles KE, Zaba LC, Shemer A. IL-22-producing "T22" T cells account for upregulated IL-22 in atopic dermatitis despite reduced IL-17-producing TH17 T cells. J Allergy Clin Immunol. 2009;123:1244-52.

98. Puya R, Alvarez-López M, Velez A, Casas Asuncion E, Moreno JC. Treatment of severe refractory adult atopic dermatitis with ustekinumab. Int J Dermatol. 2012;51:115-6.

99. Shroff A, Guttman-Yassky E. Successful use of ustekinumab therapy in refractory severe atopic dermatitis. JAAD Case Rep. 2014;1:25-6.

100. Fernández-Antón Martínez MC, Alfageme Roldán F, Ciudad Blanco C, Suárez Fernández R. Ustekinumab in the treatment of severe atopic dermatitis: a preliminary report of our experience with 4 patients. Actas Dermosifiliogr. 2014;105:312-3.

101. Weiss D, Schaschinger M, Ristl R, Gruber R, Kopp T, Stingl G, Bangert C. Ustekinumab treatment in severe atopic dermatitis: down-regulation of T-helper 2/22 expression. J Am Acad Dermatol. 2016;74:945-73.

102. Khattri S, Brunner PM, Garcet S, Finney R, Cohen SR, Oliva M, et al. Efficacy and safety of ustekinumab treatment in adults with moderate-to-severeatopic dermatitis. Exp Dermatol. 2016. doi:10.1111/exd. 13112 [Epub ahead of print].

103. Samorano LP, Hanifin JM, Simpson EL, Leshem YA. Inadequate response to ustekinumab in atopic dermatitis-a report of two patients. J Eur Acad Dermatol Venereol. 2016;30:522-3.

104. Lis-Święty A, Skrzypek-Salamon A, Arasiewicz H, Brzezińska-Wcisło L. Atopic dermatitis exacerbated with ustekinumab in a psoriatic patient with childhood history of atopy. Allergol Int. 2015;64:382-3.

105. Godse K, Mehta A, Patil S, Gautam M, Nadkarni N. Omalizumab-a review. Indian $\mathrm{J}$ Dermatol. 2015;60:381-4.

106. Johansson SGO, Oman H, Nopp A, Pettersson S. The importance of $\operatorname{IgE}$ antibody levels in anti-IgE treatment. Allergy. 2006;61:1216-9.

107. Di Lucca-Chrisment J. Dermatological implications of omalizumab, an anti-IgE antibody. Rev Med Suisse. 2015;11(779-80):782-3.

108. Andres C, Belloni B, Mempel M, Ring J. Omalizumab for patients with severe and therapy-refractory atopic eczema? Curr Allergy Asthma Rep. 2008;8:179-80.

109. Velling P, Skowasch D, Pabst S, Jansen E, Tuleta I, Grohé C. Improvement of quality of life in patients with concomitant allergic asthma and atopic dermatitis: one year follow-up of omalizumab therapy. Eur J Med Res. 2011;16:407-10.

110. Romano C, Sellitto A, De Fanis U, et al. Omalizumab for difficult-to-treat dermatological conditions: clinical and immunological features from a retrospective real-life experience. Clin Drug Investig. 2015;35:159-68.

111. Thaiwat S, Sangasapaviliya A. Omalizumab treatment in severe adult atopic dermatitis. Asian Pac J Allergy Immunol. 2011;29:357-60.

112. Park SY, Choi MR, Na JI, Youn SW, Park KC, Huh $\mathrm{CH}$. Recalcitrant atopic dermatitis treated with omalizumab. Ann Dermatol. 2010;22:349-52. 
113. El-Qutob D. Off-Label Uses of Omalizumab. Clin Rev Allergy Immunol. 2016;50:84-96.

114. Amrol D. Anti-immunoglobulin e in the treatment of refractory atopic dermatitis. South Med J. 2010;103:554-8.

115. Fernández-Antón Martínez MC, Leis-Dosil V, Alfageme-Roldán F, Paravisini A, Sánchez-Ramón S, Suárez Fernández R. Omalizumab for the treatment of atopic dermatitis. Actas Dermosifiliogr. 2012;103:624-8.

116. Forman SB, Garrett AB. Success of omalizumab as monotherapy in adult atopic dermatitis: case report and discussion of the high-affinity immunoglobulin E receptor. FcepsilonRI. Cutis. 2007;80:38-40.

117. Belloni B, Ziai M, Lim A, et al. Low-dose anti-IgE therapy in patients with atopic eczema with high serum IgE levels. J Allergy Clin Immunol. 2007;120:1223-5.

118. Holm JG, Agner T, Sand C, Thomsen SF. Omalizumab for atopic dermatitis: case series and a systematic review of the literature. Int J Dermatol. 2017;56:18-26.

119. Quist SR, Ambach A, Göppner D, et al. Long-term treatment of severe recalcitrant atopic dermatitis with omalizumab, an anti-immuno-globulin E. Acta Derm Venereol. 2013;93:206-8.

120. Vigo PG, Girgis KR, Pfuetze BL, Critchlow ME, Fisher J, Hussain I. Efficacy of anti-IgE therapy in patients with atopic dermatitis. J Am Acad Dermatol. 2006;55(1):168-70.

121. Incorvaia C, Pravettoni C, Mauro M, Yacoub MR, Tarantini F, Riario-Sforza GG. Effectiveness of omalizumab in a patient with severe asthma and atopic dermatitis. Monaldi Arch Chest Dis. 2008;69:78-80.

122. Lee E, Sheinkopf LE, Asif W, et al. Efficacy of anti-IgE therapy in patients with atopic dermatitis. J Am Acad Dermatol. 2006;55:168-70.

123. Kim DH, Park KY, Kim BJ, Kim MN, Mun SK. Anti-immunoglobulin $\mathrm{E}$ in the treatment of refractory atopic dermatitis. Clin Exp Dermatol. 2013;38:496-500.

124. Sheinkopf LE, Rafi AW, Do LT, Katz RM, Klaustermeyer WB. Efficacy of omalizumab in the treatment of atopic dermatitis: a pilot study. Allergy Asthma Proc. 2008;29:530-7.

125. Zink A, Gensbaur A, Zirbs M, et al. Targeting IgE in Severe Atopic Dermatitis with a Combination of Immunoadsorption and Omalizumab. Acta Derm Venereol. 2016;96:72-6.
126. Toledo F, Silvestre JF, Muñoz C. Combined therapy with low-dose omalizumab and intravenous immunoglobulin for severe atopic dermatitis. Report of four cases. J Eur Acad Dermatol Venereol. 2012;26:1325-7.

127. Hotze $\mathrm{M}$, Baurecht $\mathrm{H}$, Rodríguez $\mathrm{E}$, et al. Increased efficacy of omalizumab in atopic dermatitis patients with wild-type filaggrin status and higher serum levels of phosphatidylcholines. Allergy. 2014;69:132-5.

128. Heil PM, Maurer D, Klein B, Hultsch T, Stingl G. Omalizumab therapy in atopic dermatitis: depletion of IgE does not improve the clinical course-a randomized, placebo-controlled and double blind pilot study. J Dtsch Dermatol Ges. 2010;8:990.

129. Krathen RA, Hsu S. Failure of omalizumab for treatment of severe adult atopic dermatitis. J Am Acad Dermatol. 2005;53:338-40.

130. Beck LA, Thaçi D, Hamilton JD, et al. Dupilumab treatment in adults with moderate-to-severe atopic dermatitis. N Engl J Med. 2014;371:130-9.

131. Eichenfield LF, Friedlander SF, Simpson EL, Irvine AD. Assessing the new and emerging treatments for atopic dermatitis. Semin Cutan Med Surg. 2016;35:S92-6.

132. Tsianakas A, Ständer S. Dupilumab: a milestone in the treatment of atopic dermatitis. Lancet. 2016;387:4-5.

133. Lauffer F, Ring J. Target-oriented therapy: Emerging drugs for atopic dermatitis. Expert Opin Emerg Drugs. 2016;21:81-9.

134. Tsianakas A, Luger TA. The anti-IL-4 receptor alpha antibody dupilumab: facing a new era in treating atopic dermatitis. Expert Opin Biol Ther. 2015;15:1657-60.

135. Tavakolpour S. Dupilumab: a revolutionary emerging drug in atopic dermatitis and its possible role in pemphigus. Dermatol Ther. 2016;29:299.

136. Hamilton JD, Suárez-Fariñas M, Dhingra N, et al. Dupilumab improves the molecular signature in skin of patients with moderate-to-severe atopic dermatitis. J Allergy Clin Immunol. 2014;134:1293-300.

137. Simpson EL, Bieber T, Guttman-Yassky E, et al. Two Phase 3 Trials of Dupilumab versus Placebo in Atopic Dermatitis. N Engl J Med. 2016;375:2335-48.

138. Thaçi D, Simpson EL, Beck LA, et al. Efficacy and safety of dupilumab in adults with moderate-to-severe atopic dermatitis inadequately 
controlled by topical treatments: a randomised, placebo-controlled, dose-ranging phase $2 \mathrm{~b}$ trial. Lancet. 2016;2(387):40-52.

139. Simpson EL, Bieber T, Eckert L, et al. Patient burden of moderate to severe atopic dermatitis (AD): insights from a phase $2 \mathrm{~b}$ clinical trial of dupilumab in adults. J Am Acad Dermatol. 2016;74:491-8.

140. Simpson EL, Godkari A, Worm M, et al. Dupilumab therapy provides clinically meaningful improvement in patient reported outcomes (PROs): a phase IIb, randomized, placebo-controlled, clinical trial in adult patients with moderate to severe atopic dermatitis (AD). J Am Acad Dermatol. 2016;75:506-15.

141. Hamilton JD, Ungar B, Guttman-Yassky E. Drug evaluation review: dupilumab in atopic dermatitis. Immunotherapy. 2015;7:1043-58.

142. D'Erme AM. The beginning of biological treatment era in the atopic dermatitis management. Dermatol Ther. 2016;29:208-9.

143. Blakely K, Gooderham M, Papp K. Dupilumab, A monoclonal antibody for atopic dermatitis: a review of current literature. Skin Therapy Lett. 2016;21:1-5.

144. Dastidar SG, Rajagopal D, Ray A. Therapeutic benefit of PDE4 inhibitors in inflammatory diseases. Curr Opin Investig Drugs. (Review.). 2007;8:364-72.

145. Philip J. Apremilast: a phosphodiesterase 4 inhibitor for the treatment of psoriatic arthritis. Rheumatol Ther. 2014;1:1-20.

146. Fala L. Otezla (Apremilast), an Oral PDE-4 inhibitor, receives FDA approval for the treatment of patients with active psoriatic arthritis and plaque psoriasis. Am Health Drug Benefits. 2015;8(Spec Feature):105-10.

147. Samrao A, Berry TM, Goreshi R, Simpson EL. A pilot study of an oral phosphodiesterase inhibitor (apremilast) for atopic dermatitis in adults. Arch Dermatol. 2012;148:890-7.

148. Volf EM, Au SC, Dumont N, Scheinman P, Gottlieb AB. A phase 2, open-label, investigator-initiated study to evaluate the safety and efficacy of apremilast in subjects with recalcitrant allergic contact or atopic dermatitis. J Drugs Dermatol. 2012;11:341-6. 